\title{
Design and Analysis of a 5-Axis Gantry CNC Machine Tool
}

\author{
Esra Yuksel $^{1}$, Emre Özlü ${ }^{*}$, Ahmet Orall $^{2}$, Fulya Tosun ${ }^{2}$, Osman Fatih İğrek ${ }^{2}$, Erhan Budak ${ }^{1}$ \\ ${ }^{1}$ Manufacturing Research Lab, Sabanci University, Tuzla, İstanbul, Turkey \\ ${ }^{2}$ İgrek Makina Döküm Inc.,OSB A.O. Sönmez Bulv. No:10 16140 Bursa, Turkey
}

\begin{abstract}
In this study, design and analysis of a gantry-type 5-axis CNC machine tool is presented with experimental results on a manufactured prototype. Critical points in the design of a large-scaled and heavy-duty machine tool is discussed. Moreover, FE analysis results is also presented with detailed discussion. The measurement results on structural dynamics is shown together with the FE results. Furthermore, the final performance of the machine tool is demonstrated thorough position and velocity measurements of the axes.
\end{abstract}

\section{Introduction}

The fast and competitive development of aerospace, automotive and die/mould industries drive machine tool companies to offer better solutions for heavy-duty machining applications. Gantry-type machine tools are one of the most suitable structures with expandable machining span, significant structural rigidity properties and motional precision and accuracy promises [1]. A competitive heavy-duty 5-axis gantry milling machine can process workpieces that are ranged from 16 to 20 tones, with 8 to $10 \mu \mathrm{m}$ axial precision at $\mathrm{X}$ and $\mathrm{Y}$ of machine coordinates, while positional accuracy ranges from 10 to $15 \mu \mathrm{m}$ for these axes. Generally, fork head spindle structures are employed for heavy-duty 5-axis gantry-type milling machines with 95 to 120 degrees rotation capacity at A-axis, while Caxis can rotate 360 degrees. Axial and positional accuracy/precision of $\mathrm{Z}$ column can change between 3 and $5 \mu \mathrm{m}$.

In this study, the subjected 5-axis milling machine has X-axis (gantry) with length of $6700 \mathrm{~mm}$. Similarly, Y-axis has a length of $3500 \mathrm{~mm}$ Thus, there must be three main considerations as well as the other considerations mentioned in [2]: i) production technique of the machine tool components and material selection, ii) structural reliability and stiffness, iii) thermal behaviour and robustness.

Generally, welded or casted components are employed for the construction of gantrytype milling machines. The usage of welded components and joints-especially during the construction of machine base and main frames- is an emerging trend due to lower manufacturing costs compared to casted complex machine tool parts [3,4]. Moreover, welding techniques allow usage of carbon-fiber based composites in machine tool

* Corresponding author : emre.ozlu@sabanciuniv.edu 
structures which can be structurally reliable as casted components [5,6]. However, anisotropic properties of these composites cannot maintain the required stiffness levels for long structural components and spindle structures of machine tools [5]. In addition, Gas Metal Arc Welding (GMAW), Manual Metal Arc Welding (MMAW) and Laser ArcHybrid Welding (LAHW) are employed for welding of thick metal components [7], and welded materials with these techniques reaches their melting points which can cause distortion, porosity and weak material properties [8]. As a result, Y-axis strokes between 2500 and $3000 \mathrm{~mm}$ are accepted as standard lengths for large-scaled 5-axis gantry-type machine tools which are produced with welding techniques. Thus, to be able to extend the stroke of $\mathrm{X}$ and $\mathrm{Y}$ axes, casted components with superior damping properties are required to maintain the desired stiffness properties [9]. Another way to forecast and maintain the required stiffness values is employing FEM and structural optimization techniques [10], such as topology, shape or crossbeam optimizations [1,10,11]. Modelling of mechanical interfaces in FE analyses is critical during the simulation and structural optimization for even regular-sized machine tools [13]. Thus, massive component sizes and weights make contacts more critical for large-scaled machine tools. Moreover, thermal compensation techniques are not very effective for large-scaled machine tools, and thermal design/optimization requires advanced techniques for thermal distortion detection and compensation even for a medium gantry-type 5-axis CNC machine [10]. Therefore, thermal distortion preventing designs are more effective on large-scaled machine tools.

Regarding the above-mentioned facts, this study demonstrates casting method-benefited design strategies for a 5-axis gantry-type CNC machine tool. The effectiveness of the proposed strategies is evaluated with $\mathrm{FE}$ analyses and experiments on a prototype machine tool manufactured.

\section{Design of the Machine Tool and Control System}

The casting-method benefited design strategies are as follows: The main frames are designed as casted mono-block parts, which makes this design unique compared to other CNC structures in the machine tool industry. The mono-block main bodies will imitate a single-volume structure when geometric and dynamic behaviours are considered. The superiority of the casted materials over the welded ones is their ability of damping. Especially, damping ability of Gray iron is at least threefold of steel structures [14]. Frames of X and Y axes and machine base is made of GG25, and GG50 is employed to build Zaxis. The base part of the milling machine is also casted as a mono-bloc piece which weighs 24 tons. Therefore, the first mode of the structure is expected to demonstrate a mode shape of a single-volume structure. The targeted features of the machine tool are shown in Fig.1a. The $\mathrm{X}$-axis of the machine (gantry) which is longer than the usual standards, thus, the usage of casted components may not enough to maintain the required stiffness. Therefore, the internal structure of the gantry is supported with special ribbing elements. Additionally, pretensions are directed to the gantry surface during the casting process. Moreover, rails of the linear guides are casted with these mono-block components to avoid structural deformations on $\mathrm{X}$ and $\mathrm{Y}$ axes of the machine. The pretensions and casted railways are indicated in Fig.1b. Additionally, a rack and pinion mechanism based linear motion system is employed instead of classical drive screw systems. This type of a linear motion system exposes lesser efficiency losses. Moreover, the structural configuration of the rack and pinion mechanism on the gantry provides an additional support for the $\mathrm{Z}$ column as shown in Fig.1c.As mentioned earlier, thermal distortion preventing designs are more effective compared to thermal compensation techniques during design stage of large-scaled machine tools. Thus, as a cooling precaution, there are pipelines for water circulation under the slideways of $\mathrm{X}$ and $\mathrm{Y}$ axes, to keep the temperature change in the minimum. These pipes 
are inserted during the casting process. The pipeline locations for main frame cooling can be seen on the manufactured prototype in Fig.1d.

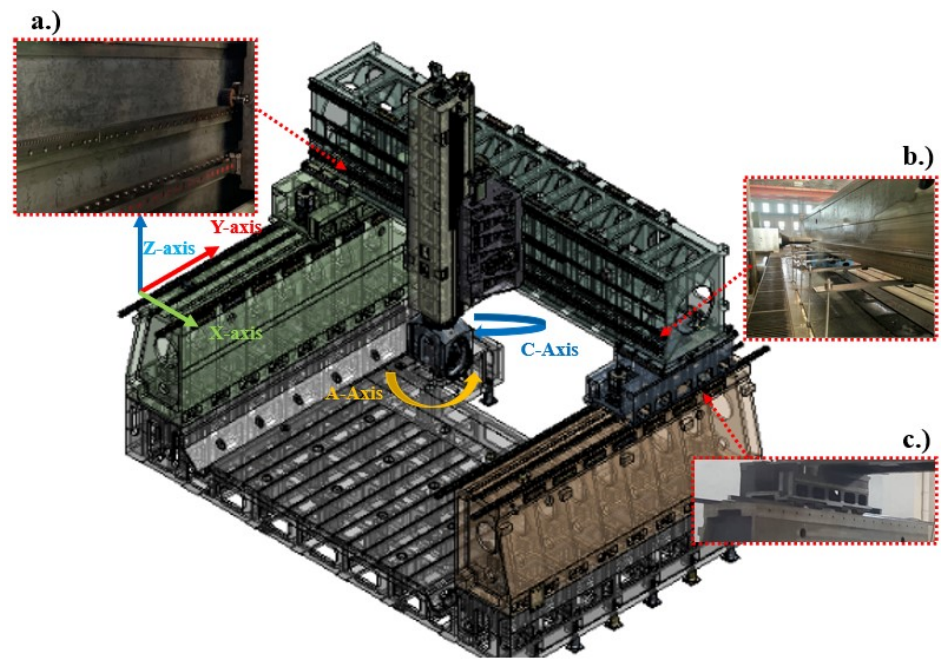

Fig.1: CAD data of the 5-axis CNC with general machine coordinates, a.) Target features b.) The pretensions on the gantry surface due to casting, and casted rails of linear guideways, c) The rack and pinion system used for linear motion system, d) The pipeline locations for the cooling of main frame.

\section{FE Analyses}

The CAD model of the assembly is simplified and composed of 377 parts in total. $14,117,354$ pyramid mesh elements are employed with 2,538,140 nodes after Jacobian and skew ratio checks. The pure penalty algorithm (prone to assign higher contact stiffness values [13]) is employed with 0.2 relaxation tolerance on the contact interfaces.

\subsection{Static Analysis}

The gravitational force is applied at the- Z-axis direction of the machine tool coordinates. The structure is fixed from the pads under the machine base. The FE model is positioned at the least stiff position to be able to detect the maximum deflection amount. The total deflection of the CNC structure is shown in Fig.2i.a. which is $0.164 \mathrm{~mm}$. Fig.2i.a. indicates that spindle-gantry connection is the weakest point of the structure. However, the total deformation of the gantry structure is predicted as $0.109 \mathrm{~mm}$ while these deformations are detected as $0.002 \mathrm{~mm}$ for X-axis. Deflection values of $0.03 \mathrm{~mm}$ and $0.09 \mathrm{~mm}$ are obtained for $\mathrm{Y}$ and $\mathrm{Z}$ axes, respectively. The directional deformations are illustrated in Fig.2b, c and $\mathrm{d}$. The maximum deformation is found as $0.002 \mathrm{~mm}$ on the X-axis, and it proves that the mono-block casted frames behave like a single volume. $0.07 \mathrm{~mm}$ and $0.149 \mathrm{~mm}$ deformation are detected on the $\mathrm{Y}$ and $\mathrm{Z}$ axes, respectively.

\subsection{Dynamic Analysis}

Subsequently, a modal analysis is employed to find the natural frequencies of the structure. The results indicate a natural frequency range between 20 and $70 \mathrm{~Hz}$, which is smaller 
compared to regular-sized machine tools. However, it is an expected result when the large sizes of the CNC structure are considered.

i.)

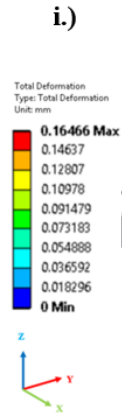

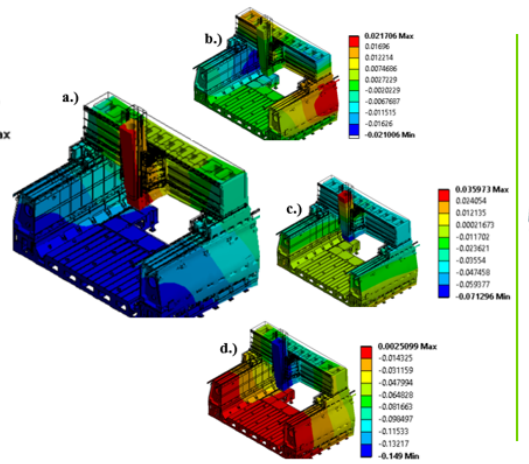

ii.)

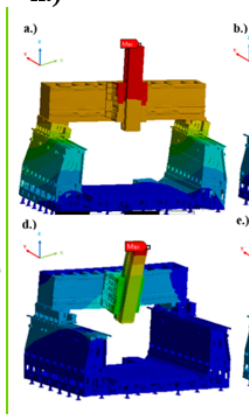

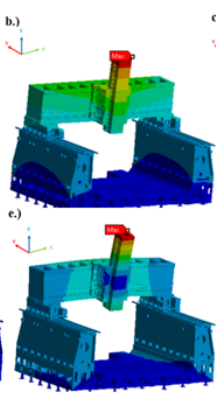

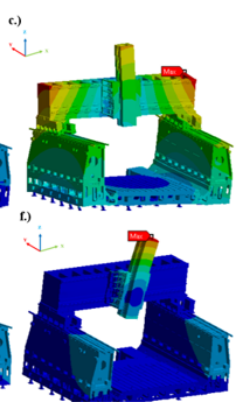

Fig.2: i.) a) The total static deformation of the $\mathrm{CNC}$ under gravitational force at the worst position. The directional static deformation results b) $\mathrm{X}$-axis, c) $\mathrm{Y}$-axis, d) $\mathrm{Z}$-axis. ii.) The mode shapes of the FE analysis. a) $1^{\text {st }}$ Mode $(21.8 \mathrm{~Hz})$, b) $2^{\text {nd }}$ Mode $(23.9 \mathrm{~Hz})$, c) $3^{\text {rd }}$ Mode $(41.8 \mathrm{~Hz})$, d) $4^{\text {th }}$ Mode $(43.8$ $\mathrm{Hz})$, e) $5^{\text {th }}$ Mode $(64.2 \mathrm{~Hz})$, f) $6^{\text {th }}$ Mode $(69.3 \mathrm{~Hz})$ shapes.

The mode shapes are indicated in Fig. 2 ii.) a, b, c, d, e and $\mathrm{f}$. The $1^{\text {st }}$ mode shape is 21.8 $\mathrm{Hz}$ and makes a swinging motion along $\mathrm{X}$-axis. The $2^{\text {nd }}$ mode shape is $23.9 \mathrm{~Hz}$, and it demonstrates a leaning motion along Y-axis. These two adjacent modes prove the casted mono-block structures behave like a single-volume structure. The $3^{\text {rd }}$ mode is around 41.8 $\mathrm{Hz}$ and shows torsional features which is undesired for machine tool design. The $4^{\text {th }}$ mode shape is $43.8 \mathrm{~Hz}$ which caused from the gantry structure. The $5^{\text {th }}$ and $6^{\text {th }}$ modes are detected as $64.1 \mathrm{~Hz}$ and $69.3 \mathrm{~Hz}$, respectively. These mode shapes are related with the Z column and gantry structures. The natural frequencies predicted by FE is expected to be lower after the $4^{\text {th }}$ mode due to contact parameters, since the related modes are related with linear guides and connection elements, however, the used contact algorithm is prone to assign higher contact stiffness values [13].

\section{Experimental Investigation}

\subsection{Modal Analysis}

FRF measurements from 25 points on the body columns are conducted by impact hammer testing. The results are presented in Table 1 together with FE results. Table 1 indicates that the natural frequencies calculated by FE analyses are close to the measured data of tests. As a result, the body components of the machine tool are produced at the predicted dynamic rigidity values. Impact Hammer tests were also conducted on the gantry which correlates the motion between $\mathrm{Y}$-axis and the $\mathrm{Z}$ column. In these measurements $20 \mathrm{FRF}$ data is collected in total. The natural frequencies and dynamic parameters obtained from the modal tests are tabulated in Table 2 together with FE analyses. As can be seen in Table 2, the $1^{\text {st }}$ Bending Mode was calculated with a lower error rate compared to the $2^{\text {nd }}$ Torsional Mode by employing FEM.

The hammer tests were performed on the $Z$ column which carries the spindle. All measurements were repeated in the XX and YY directions results in total of 36 FRF data. Impact hammer test results can be seen in Table 3. The spindle has close natural frequencies to those of the machine tool structure at the $\mathrm{X}$ and $\mathrm{Y}$ directions. However, the 
most flexible mode of the spindle in the $\mathrm{Y}$ direction is 2 times weaker than the most flexible mode in the $\mathrm{X}$ direction.

Table 1: The Comparison of the results obtained from the FE and impact hammer tests for the body columns (PCB 626B03 accelerometer, PCB 086C05 oversized hammer)

\begin{tabular}{|c|c|c|c|c|c|}
\hline \multirow{2}{*}{ Modes } & $\begin{array}{c}\text { Natural } \\
\text { Frequencies } \\
\text { obtained by } \\
\text { the FEM }(\boldsymbol{H z})\end{array}$ & \multicolumn{4}{|c|}{ The results obtained by the Impact Hammer Test } \\
\cline { 3 - 6 } & 21.8 & $\begin{array}{c}\text { Natural Frequency } \\
(\boldsymbol{H z})\end{array}$ & $\begin{array}{c}\text { Modal Stiffness } \\
(\mathbf{N} / \mathbf{m})\end{array}$ & $\begin{array}{c}\text { Damping Ratio } \\
(\%)\end{array}$ & $\begin{array}{c}\text { Receptance of } \\
\text { FRF }(\boldsymbol{\mu m} / \boldsymbol{N})\end{array}$ \\
\hline $\boldsymbol{I}^{\text {st } \text { Bending }}$ & 18.4 & $3.6 \times 10^{8}$ & 2.1 & 0.022 \\
\hline $\boldsymbol{I}^{\text {st }}$ Torsional & 41.8 & 48.8 & $4.8 \times 10^{9}$ & 0.9 & 0.011 \\
\hline
\end{tabular}

Table 2: The Comparison of the results obtained from the FE and impact hammer tests for the gantry. (PCB 626B03 accelerometer PCB 086C05 oversized hammer)

\begin{tabular}{|c|c|c|c|c|c|}
\hline \multirow{2}{*}{ Modes } & $\begin{array}{c}\text { Natural } \\
\text { Frequencies } \\
\text { obtained by the } \\
\text { FEM }(\boldsymbol{H z})\end{array}$ & \multicolumn{4}{|c|}{ The results obtained by the Impact Hammer Test } \\
\cline { 3 - 6 } & 43.8 & $\begin{array}{c}\text { Natural } \\
\text { Frequency }(\boldsymbol{H z})\end{array}$ & $\begin{array}{c}\text { Modal Stiffness } \\
(\mathbf{N} / \mathbf{m})\end{array}$ & $\begin{array}{c}\text { Damping Ratio } \\
(\%)\end{array}$ & $\begin{array}{c}\text { Receptance of } \\
\text { FRF }(\boldsymbol{\mu m} / \mathbf{N})\end{array}$ \\
\hline $\boldsymbol{1}^{\text {st }}$ Bending & 50.1 & $2.46 \times 10^{10}$ & 0.15 & 0.028 \\
\hline $\boldsymbol{1}^{\text {st }}$ Torsional & 64.2 & 84.6 & $1.33 \times 10^{10}$ & 1.30 & 0.005 \\
\hline
\end{tabular}

Table 3: The top 3 most flexible modes of the Spindle and $\mathrm{Z}$ column measured by Impact Hammer tests. (PCB 353B33 accelerometer, PCB 086C05 hammer)

\begin{tabular}{|c|c|c|c|c|c|}
\hline \multirow{2}{*}{\multicolumn{2}{|c|}{ Modes }} & \multicolumn{4}{|c|}{ The results obtained by the Impact Hammer Tests } \\
\hline & & Natural Frequency & Modal Stiffness & Damping Ratio & Receptance of \\
\hline \multirow{3}{*}{$\begin{array}{c}X X \\
\text { direction }\end{array}$} & $1^{\text {st }}$ Bending & 26.9 & $2.63 \times 10^{7}$ & 4.92 & 0.392 \\
\hline & $2^{\text {nd }}$ Bending & 89.5 & $1.31 \times 10^{8}$ & 3.92 & 0.115 \\
\hline & $3^{\text {rd }}$ Bending & 171.9 & $1.50 \times 10^{8}$ & 3.42 & 0.122 \\
\hline \multirow{3}{*}{$\begin{array}{c}Y Y \\
\text { direction }\end{array}$} & $1^{\text {st }}$ Bending & 23.7 & $2.44 \times 10^{7}$ & 2.81 & 0.823 \\
\hline & $2^{\text {nd }}$ Bending & 106.5 & $8.58 \times 10^{7}$ & 4.89 & 0.048 \\
\hline & $3^{\text {rd }}$ Bending & 190.9 & $4.98 \times 10^{8}$ & 3.31 & 0.037 \\
\hline
\end{tabular}

\subsection{Motion Performances of the Axes}

The physical capability tests were carried out to measure the velocity, acceleration and jerk behaviours of the X, Y, Z, A and C axes of the machine tool by laser sensor. The results can be seen in Figure 3.a, 3.b and 3.c for linear axes. From Figure 3.a, it can be concluded that the feed rates given to the linear axes can continuously go up to $1500 \mathrm{~mm} / \mathrm{min}$ axial velocity, and the axes can reach $1600 \mathrm{~mm} / \mathrm{min}$ axial velocity as the maximum for the feed rates that are higher than $1500 \mathrm{~mm} / \mathrm{min}$. This is caused by the $5-\mathrm{mm}$ measurement distances. A competitive regular-sized CNC with a processing capacity of - $500 \mathrm{~mm} \times 500$ $\mathrm{mm} \times 500 \mathrm{~mm}$ - volume can go up to $3500 \mathrm{~mm} / \mathrm{min}$ axial velocity at a $5-\mathrm{mm}$ distance. Therefore, the measured velocities in Figure 3.a can be considered as satisfactory when the large sizes of the machine tool are considered. The acceleration and jerk behaviours of the linear axes are indicated in Figures 3.b and 3.c, respectively. The measured maximum of accelerations and jerks are accepted as normal values compared to other competitive large scaled machine tools. The values obtained for the rotary axes can be seen in Figures 3.d, 3.e and 3.f. As can be seen from Figure 3.e, C-axis can reach $2000 \mathrm{~mm} / \mathrm{min}$ feed rate properly, while A-axis could not catch this value. 
a.)

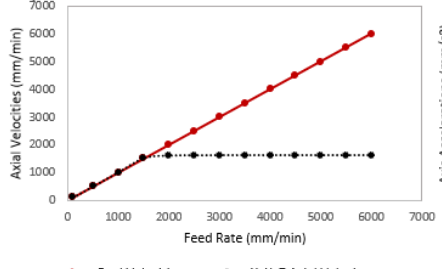

. Real Velocitiy $\quad$........ $x, y, z$ Axial Velocity

d.)

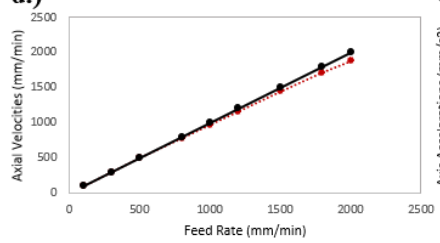

b.)

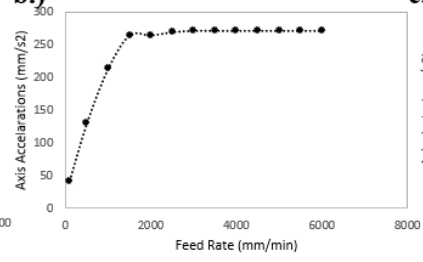

e.)

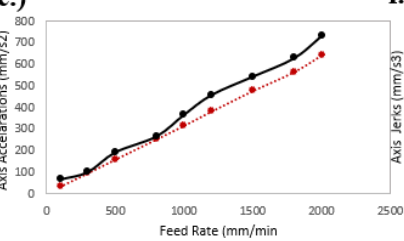

c.)

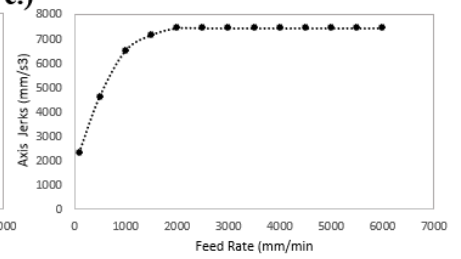

f.)

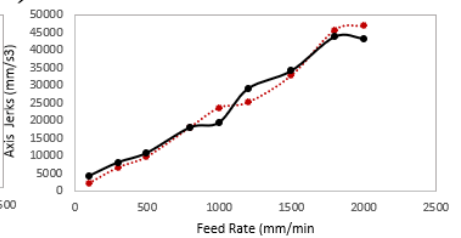

Fig.3: a.) Linear Axial Velocities, b.) Linear Axial Accelerations, c) Linear Axial Jerk profiles of X, $\mathrm{Y}, \mathrm{Z}$ axes for a 5-mm translation; e.) Rotational Axial Velocities, d.) Rotational Axial Accelerations, f) Rotational Axial Jerk profiles of $\mathrm{A}$ and $\mathrm{C}$ axes for $3^{\circ}$ rotation.

\section{Conclusions}

Design and analysis methods are presented for a gantry-type machine tool with large sizes. The significance of casted mono-block components is emphasized to enable the structural rigidity during the manufacturing of these massive structures. Casting-method benefited design strategies are proposed to maintain the stiffness values to build a large-sized gantrytype CNC machine tool. The effectiveness of the proposed methods was evaluated by FE analyses and experiments special to machine tools on the manufactured prototype. The results indicate competitive performance by using the proposed casting-method benefited design strategies.

\section{References}

1. S. Liu, Y. Li, Y. Liao, Z. Guo, Str. and Mult. Opt, 50, 2, 297-311. (2014).

2. X. Yang, K. Cheng, Procedia Manufacturing, 11, 1454-1462, (2017).

3. P. Boral, T. Nieszporek, R. Gołębski, MATEC Web of Conf., 157, (EDP Sci, 2018).

4. M. Guillo, L. Dubourg, Robotics and CIM, 39, 22-31, (2016).

5. J. Do Suh, H.S. Kim, J.M. Kim, Comp. Sci. Tech., 64, 10-11, 1523-1530, (2004).

6. E.F. Kushnir, M.R. Patel, T.M. Sheehan, ASME-PUBS.-PVP, 432, 133-146, (2001).

7. G. Sproesser, Y.J. Chang, A. Pittner, M. Finkbeiner, M. Rethmeier, Sustainable Manufacturing, 71-84, (Springer, Cham., 2017).

8. X. Lu, X. Lin, M. Chiumenti, M. Cervera, Y. Hu, X. Ji, W. Huang, Additive Manufacturing, 26, 166-179, (2019).

9. R. Schaller, Journal of Alloys and Compounds, 355, 1-2, 131-135, (2003).

10. Y. Altintas, C. Brecher, M. Weck, S. Witt, CIRP annals, 54, 2, 115-138, (2005).

11. L. Zhang, L. Ma, D. Wu, Y. Zhou, The Int. J. of Adv. Manuf. Tech., 104,1-4, 245-260, (2019).

12. W.U. Tao, L.G. CAI,. DEStech Tr. on Eng. and Tech. Res., (amee), (2018).

13. E. Yuksel, A.S. Erturk, E. Budak, E. J. of Manuf. Sci. and Eng., 142, 8, (2020).

14. T. Murakami, T. Inoue, H. Shimura, M. Nakano, S. Sasaki, Mat.Sci.and Eng, A, 432, 12, 113-119. (2006). 